\title{
Custo e resultados do tratamento de seqüelas de laminite bovina: relato de 112 casos em vacas em lactação no sistema free-stall
}

\author{
[Results and costs of treatment for bovine laminitis sequelae: \\ study of 112 lameness cases in lactating cows in free-stall system] \\ P.M. Ferreira, R.C. Leite, A.U. Carvalho, E.J. Facury Filho, R.C. Souza, M.G. Ferreira \\ Escola de Veterinária - Universidade Federal de Minas Gerais \\ Caixa Postal 567 \\ 30123-970 - Belo Horizonte, MG
}

\section{RESUMO}

Os resultados e o custo do tratamento de seqüelas podais da laminite subclínica são descritos em 112 casos de manqueira em vacas em lactação mantidas no sistema free-stall. As observações feitas durante um ano abrangeram animais de 2,5 a 10 anos de idade, da primeira à sexta lactação e com média de produção de $8.000 \pm 2.000 \mathrm{~kg}$ de leite. O protocolo de tratamento, descrito detalhadamente para cada uma das afecções podais, foi eficiente na reversão de todas elas. $\mathrm{O}$ custo total do tratamento para o rebanho foi de US\$5,005.23, equivalente ao custo médio de US\$44.68 por animal. O tratamento das úlceras de sola foi o mais dispendioso (US\$72.58) e o mais demorado (26,8 dias). As afecções mais comuns foram os abscessos de sola e do talão e as lesões da linha branca (64/112 ou 57,2\%).

Palavras-chave: bovino leiteiro, laminite, tratamento, custo

\begin{abstract}
The results and costs of treatments of feet sequelae of subclinic dairy cattle laminitis were described in 112 cases of lameness in lactating cows maintained in free stall system. The analyses were performed in an one-year-period using 2.5 to 10 year-old, first to sixth parity cows. Average milk yield was $8,000 \pm 2,000 \mathrm{~kg}$. The treatment protocol was described in details for each digit lesion and it was very successful to reverse all kinds of lesions. The total treatment cost for the herd was US\$5,005.23 and the mean cost/animal was US\$44.68. The ulcer treatments were costly (US\$72.58) and longer (26.8 days). Sole and heel abscesses and white line disease at the foe (64/112 or 57.2\%) were most commonly observed.
\end{abstract}

Keywords: dairy cattle, laminitis, treatment, cost

\section{INTRODUÇÃO}

A manqueira em vacas leiteiras, principalmente a que causa prejuízos à produção, tem incentivado a pesquisa em todo o mundo. Suas altas taxas de prevalência e incidência, especialmente em animais confinados, requerem medidas eficazes

Trabalho financiado pela FAPEMIG

Recebido para publicação em 29 de setembro de 2003

Recebido para publicação, após modificações, em 30 de agosto de 2004

E-mail: ferreira@vet.ufmg.br de tratamento e controle, para minimizar as perdas da produção de leite, a queda dos índices reprodutivos e zootécnicos, os descartes prematuros e a morte de animais. No entanto, a literatura é omissa e freqüentemente contraditória no detalhamento de protocolos de tratamento e controle da doença. 
Entre as causas de manqueira em vacas de leite destaca-se a laminite - processo inflamatório das lâminas do cório, de etiologia multifatorial, associado a distúrbios da microcirculação e que leva a disrupção da função derme/epiderme e mal-formação da camada córnea. As conseqüências são hemorragias na sola, talão e linha branca, alterações de cor dos apêndices córneos, lesões da linha branca, úlceras da sola e da pinça, aparecimento de sola dupla, fissuras da muralha e erosões do talão.

A porcentagem de cura e rápida recuperação das lesões pode ser alta desde que se façam intervenções prontas e corretas. Normalmente os procedimentos são cirúrgicos e requerem anestesia local. A técnica anestésica mais utilizada é a injeção endovenosa de um anestésico local (cerca de 10 a $20 \mathrm{ml}$ de lidocaína a $2 \%$, aplicado na veia digital dorsal plantar/palmar após a colocação de torniquete (manguito de borracha) na região metacarpiana/metatarsiana.

Os casos de processos purulentos, independentemente da localização, devem ser tratados por ressecção da lesão e drenagem do exsudato com eliminação dos tecidos necrosados. Quando já existe tecido de granulação, é necessário removê-lo. Muitas vezes é aconselhável o uso de antibióticoterapia parenteral, durante três dias, e amputação da falange, caso o processo seja grave e profundo.

O corte da unha lesada é muitas vezes recomendado, já que permite o descanso e o alívio do peso sobre ela. Sua retirada total deve ser feita sempre com uma rineta afiada, procurando-se provocar o mínimo de hemorragia, mas promovendo uma limpeza profunda dos tecidos necrosados. Só assim poderá se esperar uma cicatrização rápida e adequada.

Nos casos de úlceras da sola, deve-se reduzir ao máximo a pressão sobre ela, fazendo um casqueamento adequado e ressecção do tecido de granulação. Não é recomendável o uso de bandagens, por provocar pressão sobre a lesão e manter alta a umidade no local, propiciando infecção secundária e retardamento da cicatrização (Greenough e Weaver, 1997). Se se usar bandagens, elas devem ser renovadas periodicamente para se manterem secas e podem ser bom recurso terapêutico junto com o uso de tamancos (Sagüés e Mazzucchelli, 1998). Segundo Pyman (1997), a taxa de recuperação com o uso de bandagens é maior, especialmente nas duas primeiras semanas de tratamento. Já a erosão do talão deve ser tratada por remoção dos tecidos córneos necrosados, retirada das fissuras (se presentes), aplicação de adstringentes ou antibióticos em spray e alojamento do animal em local limpo e seco (Greenough e Weaver, 1997; Sagüés e Mazzucchelli, 1998). Para as úlceras de pinça não existem referências consistentes de tratamento.

Eliminar o apoio do casco doente é muitas vezes a chave do tratamento das lesões podais. A cura pode ser obtida pela colocação de tamancos nas unhas sadias e, com isso, aliviar a dor e a pressão sobre a unha doente. Essa conduta deve ser realizada depois de feito o nivelamento das unhas sadias, para melhorar seu apoio, com grosa manual ou disco de lixa adaptado a furadeira elétrica. $O$ tamanco de 11 a $13 \mathrm{~cm}$ de comprimento por $2,5 \mathrm{~cm}$ de espessura deve se fixado com cola ou cravos de ferradura. Esse recurso terapêutico mostrou-se bastante eficiente segundo as observações de Greenough e Weaver (1997) e Sagüés e Mazzucchelli (1998).

O objetivo do presente estudo foi o de testar protocolos de tratamento das principais conseqüências da laminite subclínica em rebanhos leiteiros confinados em sistema freestall, determinando seus resultados e custo.

\section{MATERIAL E MÉTODOS}

Foram determinados os resultados e os custos do tratamento de 112 casos de seqüelas de laminite em vacas em lactação e mantidas no sistema free-stall. As observações feitas durante 0 período de um ano abrangeram animais entre 2,5 e 10 anos de idade, da primeira à sexta lactação e com média de produção de $8.000 \pm 2.000 \mathrm{~kg}$ de leite. O sistema de manejo foi uniformizado e incluía ordenha duas a três vezes ao dia, conforme taxa de produção, e arraçoamento três vezes ao dia, em pista de trato, com silagem de milho, concentrado misturado na própria fazenda e sal mineral à vontade. O concentrado era fornecido na proporção de $1 \mathrm{~kg} / 3 \mathrm{~kg}$ de leite e o volumoso, à vontade. Para a ordenha ou arraçoamento, os animais desciam uma rampa de 
cascalho de aproximadamente $3 \mathrm{~m}$ de comprimento com inclinação maior que $10 \%$, caminhavam cerca de $100 \mathrm{~m}$ sobre piso de cimento até a sala de espera da ordenha, ultrapassando 10 degraus entre a entrada e a saída, e passavam por pedilúvio com formalina a 3\%. A higienização dos estábulos e da pista de trato era realizada uma vez por dia por raspagem.

A seleção dos casos para tratamento foi feita por exame clínico detalhado nos animais que apresentavam manqueira. Estes eram levados ao tronco de casqueamento, tinham os cascos limpos e examinados por inspeção, palpação, movimentação articular, percussão com martelo e plessímetro (verificação de dor), pressão com pinça de casco e limpeza superficial do estrato córneo com rineta suíça. Verificada a presença de lesão, esta era completamente exposta com auxílio de rineta convencional e caracterizada conforme classificação de Grenough e Weaver (1997), adaptada às condições deste estudo. Em seguida era determinado o tratamento a ser instituído.

Após limpeza rigorosa do casco com água corrente e escova de aço flexível, também o espaço interdigital era limpo com água corrente e com o auxílio de faixa crepe. Se as lesões do estrato córneo eram graves, o casco sadio era preparado para a colocação de tamanco. Com esmeril de $115 \mathrm{~mm}$ de diâmetro e disco flap $\mathrm{n}^{\circ} 40$ a sola era nivelada e feita a limpeza superficial da muralha nos sentidos axial, abaxial e dorsal, para permitir melhor aderência da resina acrílica ao casco e ao tamanco.

O tamanco de madeira Ipê, com $11 \times 5,5 \times 2,5 \mathrm{~cm}$ de comprimento/largura/espessura era fixado ao casco com resina acrílica ${ }^{1}$ assim preparada: $52 \mathrm{~g}$ do componente $A$ era adicionada a $30 \mathrm{ml}$ do componente $B$, misturando-se com espátula metálica até a total homogeneização e formação de massa firme. Essa massa era dividida em quatro partes e aplicadas, respectivamente, (1) sobre o tamanco (colagem na sola), (2) sobre a muralha abaxial, parte do talão e parte do tamanco, (3) sobre a muralha axial e parte do tamanco e (4) sobre a muralha dorsal, pinça e parte do tamanco. Para secagem rápida da massa

${ }^{1}$ Acrílico Acri-Jet autopolimerizante acrílica era usada uma pistola sopradora de ar quente $^{2}$.

Nos casos de lesões graves para as quais procedimentos cirúrgicos são recomendados, fazia-se a anestesia do dígito lesado pela aplicação de $5-10 \mathrm{ml}$ de lidocaína a $2 \%$, sem vasoconstritor, na veia digital superficial dorsal ou plantar/palmar, conforme o caso, após garroteamento da região metatarsiana ou metacarpiana. Para a visualização dos tecidos necrosados e descolados da derme da sola, muralha e talão, era utilizada uma sonda metálica de $2 \mathrm{~mm}$ de diâmetro $\times 20 \mathrm{~cm}$ de comprimento. A remoção desses tecidos era feita com rinetas, facas em L, bisturi de lâmina fixa $n^{0} 4$, cureta dupla de Volkman de $15 \times 6 \times 200 \mathrm{~mm}$, mantidas em solução de digluconato de clorexidina ${ }^{3}$ a $0,1 \%$. Após a remoção dos tecidos necrosados, a área era lavada com solução de iodo antisséptico e aplicação tópica de iodo a $10 \%$. Sobre feridas era aplicada pasta de furazolidona ${ }^{4}$ e tetraciclina em pó ${ }^{5}$, cobrindo-se com gaze. Caso houvesse risco de hemorragia profusa, uma boneca de algodão e gaze era usada para comprimir os tecidos. A coroa do casco era então protegida com algodão ortopédico e a unha lesada enfaixada com atadura elástica $(0,1 \times 3 \mathrm{~m})$. Essa bandagem era recoberta com emulsão asfáltica ${ }^{6}$.

Semanalmente era feita a revisão das feridas e a avaliação da evolução do processo cicatricial. Havendo necessidade, fazia-se a troca das bandagens. Nos casos de úlcera da sola e da pinça, fazia-se a remoção do estrato córneo original ao redor das lesões, para facilitar o recobrimento com o estrato córneo neoformado, evitando-se o acúmulo de matéria orgânica debaixo da sola e possível abscedação.

Para avaliar os custos do tratamento, foi estabelecido o tempo de 40 minutos para os procedimentos cirúrgicos e 20 minutos para as revisões semanais após o tratamento. Esse tempo foi transformado em custos considerando-se os honorários do médico veterinário e o salário de seu auxiliar ou tratador da fazenda. O custo do material e medicamentos foi convertido em US\$

\footnotetext{
${ }^{2}$ Pistola sopradora de ar quente COMALA, $1.400 \mathrm{~W}, 300$ $500^{\circ} \mathrm{C}$

${ }^{3}$ Sterilan (Pearson)

${ }^{4}$ Furacin (Shering Plough)

${ }^{5}$ Terramicina pó TPS (Pfizer)

${ }^{6}$ Frio Asfalto (Vedacit)
} 
da época (1US\$= R $\$ 2,20)$. Os custos de deslocamento da equipe técnica foram incluídos no custo da assistência veterinária.

Os resultados foram avaliados por análise descritiva simples.

\section{RESULTADOS E DISCUSSÃO}

$\mathrm{Na}$ propriedade estudada, a freqüência de animais acometidos de lesões podais conseqüentes a laminite era de 78,3\% (112/143). As manifestações sistêmicas da laminite foram discretas ou passaram despercebidas, daí o quadro ter sido considerado típico das laminites subclínicas. Os abscessos de sola e talão e as lesões da linha branca foram as alterações podais mais freqüentes $(57,2 \%, 64 / 112)$. As demais alterações tiveram freqüência menor, como demonstra a Tab. 1. Seis vacas apresentaram concomitantemente às lesões podais artrose e ancilose da falange média/distal.

Tabela 1. Freqüência das lesões podais secundárias à laminite em vacas em lactação mantidas no sistema free-stall

\begin{tabular}{lcc}
\hline Lesão podal & $N^{\circ}$ de casos & Freqüência (\%) \\
\hline Abscesso de sola e talão & 35 & 31,3 \\
Lesão da linha branca & 29 & 25,9 \\
Úlcera de sola & 18 & 16 \\
Erosão de talão & 15 & 13,4 \\
Sola dupla & 9 & 8 \\
Úlcera de pinça & 5 & 4,5 \\
Hemorragia de sola & 1 & 0,9 \\
Total & 112 & 100 \\
\hline
\end{tabular}

A freqüência de animais acometidos é alta, demonstrando a importância da laminite na gênese de alterações dos cascos em rebanhos leiteiros confinados, e pouco diferem daquela encontrada em outras partes do mundo (Greenough, 1994; Smile et al., 1996; Greenough e Weaver, 1997; Van Amstel e Shearer, 2001; Lischer e Ossent, 2002).

Os procedimentos usados no tratamento das lesões mostraram ser os mais adequados, já que em todos os animais houve cura das lesões num período máximo médio de 26,8 dias. Esse período foi bem menor do que o obtido por Borges et al. (1995) que só observou reversão das lesões podais num período médio de 45,6 dias e contradiz a assertiva de Mgasa (1987) que as seqüelas das laminites subclínicas são na maioria irreversíveis. Em cinco casos de úlcera da pinça os resultados do tratamento não foram conclusivos. Mesmo os animais portadores de artrose e ancilose, que apresentavam número elevado de lesões dos vários tipos, responderam aos tratamentos tal como a média dos animais.

Ao final do experimento, esses eram os únicos animais recomendados para descarte, dada a anquilose, correspondendo a uma taxa anual de descarte de 5,1\% do rebanho (6/117).

Algumas vezes, pela persistência do tecido de granulação durante a cicatrização, era necessária a nova curetagem profunda da área lesada para que a resposta terapêutica fosse satisfatória. Em muitos casos de lesões da linha branca era necessária a retirada da muralha no foco da lesão ou mesmo até a região coronariana, diferindo do preconizado por vários autores de que a muralha deve ser retirada somente a um ângulo de $45^{\circ} \mathrm{em}$ relação à linha branca (Allenstein, 1994; Greenough e Weaver, 1997; Greenough, 2000; Van Amstel e Shearer, 2001).

A anestesia local venosa, usada em todos os casos que requereram procedimentos cirúrgicos invasivos, demonstrou ser muito eficiente e econômica. A dose utilizada, cerca de $5-10 \mathrm{ml}$ de lidocaína a $2 \%$, foi inferior à preconizada por Borges et al. (1995), Greenough e Weaver (1997) e Sagüés e Mazzucchelli (1998), provavelmente porque os procedimentos foram sempre rápidos e a aplicação do anestésico só se fazia quando toda a preparação pré-cirúrgica já havia terminado.

O uso de tamancos, especialmente nos casos de abscessos de sola/talão, lesões da linha branca e úlceras de sola e pinça, reduziu o peso sobre a unha lesada e foi decisivo para o sucesso do tratamento, tal como observado também por Allenstein (1994), Greenough e Weaver (1997), Pyman (1997), Sagüés e Mazzucchelli (1998).

A durabilidade da fixação dos tamancos com resina parece ser influenciada pela forma de preparação da mistura acrílica. Nas proporções usadas neste estudo $(50 \mathrm{~g}$ ou $70 \mathrm{ml}$ do componente acrílico em pó para $24 \mathrm{~g}$ ou $30 \mathrm{ml}$ do componente líquido) conseguiu-se uma massa mais homogênea, pouco aderente às mãos e 
muito resistente às condições de piso enfrentadas pelos animais (rampas e degraus). Isso determinou um período de fixação do tamanco, muito maior do que o conseguido por Sagüés e Mazzucchelli (1998), ao usarem as proporções recomendadas pelo fabricante, e por Pyman (1997), que usou 80g do componente em pó para $40 \mathrm{~g}$ do líquido. Além da maior durabilidade os custo foram menores, dada à menor quantidade de resina utilizada. Já o tamanco em si, confeccionado em ipê, teve durabilidade superior a 30 dias, tempo suficiente para a cura das lesões, tornando-o altamente recomendado. No preparo do casco para a inserção do tamanco, o uso de esmerilhadeira com disco flap permitiu melhor limpeza da muralha e melhor nivelamento da sola, com conseqüente aumento da aderência da resina acrílica. Além disso, o disco flap parece ser mais durável que o disco de lixa, possuindo também maior eficiência no desbaste dos tecidos córneos.

A conduta pós-cirúrgica (assepsia com iodo, aplicação de solução de iodo a $10 \%$ e pasta de furazolidona com tetraciclina, bandagem com impermeabilizante asfáltico) permitiu a permanência do curativo por até sete dias, tempo suficiente para se obter boa cicatrização das feridas cirúrgicas. Com isso dispensaram-se as constantes trocas de curativo preconizadas por Pyman (1997) e Sagüés e Mazzucchelli (1998) que não utilizam a impermeabilização das bandagens. Greenough e Weaver (1997) não recomendam bandagens, principalmente nas úlceras de sola, dada a compressão que elas exercem. Neste estudo as bandagens eram colocadas evitando-se grande pressão e, como eram impermeabilizadas, as feridas permaneciam secas, favorecendo a cicatrização.

Nos casos de abscessos, bons resultados foram obtidos sem tamponamento com drenos, contrariando a indicação de Shearer (1998), e sem administração parenteral de antibióticos como preconizado por Allenstein (1994), Greenough e Weaver (1997) e Ramos (1999). Em nenhum caso foi necessária a amputação da falange distal, demonstrando o sucesso do tratamento em circunscrever e eliminar o processo supurado.

Os custos e tempo do tratamento, bem como o número de intervenções, são detalhados nas Tab. 2 e 3 .

Tabela 2. Custo unitário e total dos procedimentos terapêuticos, segundo as lesões podais, em 112 casos de seqüelas de laminite em vacas em lactação, mantidas em sistema free-stall

\begin{tabular}{|c|c|c|c|c|c|}
\hline \multirow{2}{*}{ Lesão podal } & \multirow{2}{*}{$\mathrm{N}^{\mathrm{o}}$ de casos } & \multicolumn{2}{|c|}{ Custo do procedimento (US\$)* } & \multirow{2}{*}{ Custo unitário } & \multirow{2}{*}{ Custo total } \\
\hline & & Cirurgia & Curativo & & \\
\hline Abscesso de sola/talão & 35 & 28.84 & 19.62 & 48.48 & $1,698.80$ \\
\hline Lesão da linha branca & 29 & 14.56 & 23.00 & 37.56 & $1,089.24$ \\
\hline Úlcera de sola & 18 & 47.58 & 25.00 & 72.58 & $1,306.44$ \\
\hline Erosão de talão & 15 & .78 & 22.62 & 23.40 & 351.00 \\
\hline Sola dupla & 9 & 26.00 & 7.75 & 33.75 & 303.75 \\
\hline Ùlcera de pinça & 5 & 26.00 & 26.00 & 46.00 & 230.00 \\
\hline Hemorragia de sola & 1 & 26.00 & & 26.00 & 26.00 \\
\hline Total & 112 & & & & $5,005.23$ \\
\hline
\end{tabular}

*O valor do procedimento cirúrgico e do curativo foi estimado em US\$26.00 e US\$12.50, respectivamente, considerando o tempo gasto de $40 \mathrm{~min}$ para a cirurgia e $20 \mathrm{~min}$ para o curativo e somados os honorários do veterinário (incluída a quilometragem de deslocamento) e o salário do tratador, bem como o custo médio do material utilizado.

O custo total do tratamento dos 112 casos de lesões podais relacionadas a laminite foi de US\$5,005.23, representando um custo unitário de US\$44.68. O tratamento das úlceras de sola foi o de maior custo, exatamente pelo maior número de intervenções e de dias de tratamento (Tab. 3).
Harris el al. (1988) verificaram custos semelhantes na Austrália, mas Ramos (1999) observou um valor um pouco superior no Estado de Goiás, BR, ou seja, R\$133,29, o que equivale a US\$51.50. 
Tabela 3. Número médio de procedimentos terapêuticos e média de dias de tratamento, segundo as lesões podais em 112 casos de seqüelas de laminite em vacas em lactação mantidas em sistema free-stall

\begin{tabular}{lccc}
\hline \multirow{2}{*}{ Lesão podal } & \multicolumn{2}{c}{ Número médio } & \multirow{2}{*}{$\begin{array}{c}\text { Dias de } \\
\text { de procedimentos }\end{array}$} \\
\cline { 2 - 3 } & Cirurgia & Curativo & \\
\hline Abscesso de sola/talão & 1,83 & 2 & 26,8 \\
Lesão da linha branca & 1 & 1,6 & 18,2 \\
Úlcera de sola & 1,1 & 1,57 & 18,7 \\
Erosão de talão & 0,56 & 1,84 & 16,8 \\
Sola dupla & 1 & 0,62 & 11,3 \\
Ùlcera de pinça & 0,78 & 1,81 & 18,1 \\
Hemorragia de sola & 1 & & 7 \\
Média geral & 1,02 & 1,62 & 18,7 \\
\hline
\end{tabular}

Somados os custos do tratamento e o valor do descarte das seis vacas (US\$3,727.27), as seqüelas da laminite provocaram perda anual de US\$8,732.50, o que equivale a um prejuízo de US\$74.60 por animal alojado no rebanho (117 animais). Essa perda foi além dos US\$9.76 por animal computados por Borges et al. (1995) em rebanhos Girolanda e Holandês mantidos em sistema semi-confinado, mas inferior àquela observada por Shearer et al. (1999) que consideraram também as perdas na produção de leite e com os distúrbios reprodutivos. Fica claro com isso que mesmo com o sucesso do tratamento os prejuízos causados aos rebanhos leiteiros pela laminite subclínica e suas seqüelas podais são bastante expressivos.

\section{CONCLUSÕES}

As seqüelas podais da laminite subclínica provocam perdas econômicas expressivas aos rebanhos leiteiros mantidos em sistema free-stall mesmo quando há sucesso no tratamento. O protocolo de tratamento testado, além de efetivo na resolução das afecções podais secundárias à laminite subclínica, é economicamente viável. Todas as modificações imprimidas ao protocolo terapêutico tradicional, por sua eficácia, são recomendadas para sistemas de exploração leiteira semelhantes. Nas afecções purulentas, o uso parenteral de antibióticos é desnecessário, devendo se a antibióticoterapia restringir-se apenas ao local da lesão.

\section{REFERÊNCIAS BIBLIOGRÁFICAS}

ALLENSTEIN, L.C. Distúrbios da locomoção dos bovinos. In: SIMPÓSIO INTERNACIONAL SOBRE PRODUÇÃO INTENSIVA DE LEITE. Interleite, 1994. Anais... São Paulo, 1994. P.53-65

BORGES, J.R.; SANTIAGO, S.F.; DA SILVA, N.L. et al. Custos de tratamento e descarte causados por doenças digitais em rebanho leiteiro. Rev. Bras. Clin. Vet., v.2, p.23-25, 1995.

GREENOUGH, P.R. Diseases of feet of dairy cows. CONGRESSO BRASILEIRO DE CIRURGIA E ANESTESIA, 2000. Anais ... Goiânia, 2000. P.1-20.

GREENOUGH, P.R. Structure and function of the digit. In: SYMPOSIUM ON DISORDERS OF RUMINANT DIGIT, 8., 1994. Proceedings... Banff: University of Saskatchewan, 1994. P.305

GREENOUGH, P.R.; WEAVER, A.D. Lameness in cattle. 3.ed. Philadelphia: W.B. Saunders, 1997. 336p.

HARRIS, D.J.; HIBBURT, G.A.; ANDERSSON, G.A. et al. The incidence, cost and factors associated with foot lameness in dairy cattle in South-Western Victoria. Aust. Vet. J., v.65, p.171-176, 1988.

HOBLET, K.H.; WEISS, W. Metabolic hoof horn disease. Vet. Clin North Am.: Food Anim. Pract., v.17, p.111-127, 2001.

LISCHER, C.J.; OSSENT, P. Pathogenesis of sole lesions attributed to laminitis in cattle. In: INTERNATIONAL SYMPOSIUM ON DISORDERS OF RUMINANT DIGIT, 12., 2002. Proceedings... Orlando, 2002. P.82-89.

MGASA, M.N. Bovine pododermatitis diffuse (laminitis): aetiology, pathogenesis, treatment and control. Vet. Res. Comm., v.11, p.235-241, 1987.

PYMAN, M.F.S. Comparison of bandaging and elevation of claw for treatment of foot lameness in dairy cows. Aust. Vet. J., v.75, p.132-135, 1997.

RAMOS, L.S. Avaliação econômica dos efeitos da pododermatite sobre a produção dis bovinos. 1999. $113 \mathrm{f}$. Tese (Mestrado). Escola de Veterinária, Universidade Federal de Goiás, Goiânia, GO.

SAGÜÉS, G.A.; MAZZUCCHELLI, F. Control de cojeras en el Ganado vacuno de leche. Tratado de veterinária práctica bovis. Madrid: Luzáns, 1998. P.66-76.

SHEARER, J.K. Lameness of dairy cattle: consequences and causes. Bov. Practit., v.32, p.79-85, 1998.

SHEARER, J.K.; VAN AMSTEL, S.R.; MELENDEZ, P. Manual para el programa de recortador de pezuñas, cojeras en el ganado lechero. 1999. 55f. Notas de aula - University of Florida, Gainesville, Florida.

SMILE, R.H.; HOBLET, K.H.; WEISS, W.P. et al. Prevalence of lesions associated with subclinical laminitis in first-lactation cows from herds with high milk production. $J$. Am. Vet. Med. Assoc., v.208, p.1445-1451, 1996.

VAN AMSTEL, S.R.; SHEARER, J.K Abnormalities of hoof growth and development. Vet. Clin. North Am.: Food Anim. Pract., v.17, p.73-91, 2001. 